\title{
International Journal of Applied Behavioral Economics
}

\section{April-June 2015, Vol. 4, No. 2}

\section{Table of Contents}

\section{Research Articles}

1 A Random Utility Model for Shareholders Capturing the Disposition Effect Alfred Ka Chun Ma, CASH Axiom Capital Limited, Hong Kong Justina Yuen Ki Cheung, J.P. Morgan, Hong Kong

16 On Design and Development of QLIFEX: An Expert System for Social Area Irena Atanasova, Department of Informatics, South-West University "Neofit Rilski", Blagoevgrad, Bulgaria \& Faculty of Economics, University of Pardubice, Pardubice, Czech Republic

36 Behavioral Health and Relational Dynamics David S. Bathory, Psychology Department, Bathory International LLC, Somerville, NJ, USA

53 The Contribution of the UK's Behavioural Insights Team

Simon James, Department of Organization Studies, University of Exeter Business School, Exeter, $U K$

Copyright

The International Journal of Applied Behavioral Economics (IJABE) (ISSN 2160-9802; eISSN 2160-9810), Copyright (C) 2015 IGI Global. All rights, including translation into other languages reserved by the publisher. No part of this journal may be reproduced or used in any form or by any means without written permission from the publisher, except for noncommercial, educational use including classroom teaching purposes. Product or company names used in this journal are for identification purposes only. Inclusion of the names of the products or companies does not indicate a claim of ownership by IGI Global of the trademark or registered trademark. The views expressed in this journal are those of the authors but not necessarily of IGI Global.

The International Journal of Applied Behavioral Economics is indexed or listed in the following: Bacon's Media Directory; Cabell's Directories; Google Scholar; INSPEC; JournalTOCs; MediaFinder; RePEc; The Standard Periodical Directory; Ulrich's Periodicals Directory 


\title{
The Contribution of the UK's Behavioural Insights Team
}

\author{
Simon James, Department of Organization Studies, University of Exeter
} Business School, Exeter, UK

\begin{abstract}
The purpose of this paper is to review and evaluate the work of the UK Behavioural Insights Team (BIT) in the light of the growing literature on behavioural economics. The Team was established in 2010 in the Cabinet Office at the centre of government in the UK. The BIT was specifically set up with the aim of helping the government develop and apply lessons from behavioural economics and behavioural science to public policy. A direct link with the behavioural literature took place when the book Nudge by Richard Thaler and Cass Sunstein (2008) became 'required reading' on a 2008 summer reading list for Conservative Members of Parliament since their views are seemingly consistent with the Conservative Party's tax and welfare policies. For this reason the Behavioural Insights Team is often known as the 'Nudge Unit'. At the time of writing (May 2014) it has been announced that the unit will be moved outside government to continue its work, though government (and others) can continue to use its services. This paper analyses a series of reports published by the BIT and concludes that those on health policy, organ donation and charitable giving used behavioural insights to a considerable extent while two of the reports on financial aspects did so to a lesser extent and another one on financial matters hardly at all. It is suggested that some areas may have more potential than others for the application of behavioural insights but that such potential also exists with respect to financial behaviour.
\end{abstract}

Keywords: Behavioural Insights Team, Consumer Decisions, Decision-Making, Nudging, United Kindgdom (UK)

DOI: $10.4018 /$ ijabe.2015040104 


\section{INTRODUCTION}

It has been estimated that in the UK behavioural and lifestyle factors are significant contributors in around half of all deaths. These factors including smoking, unhealthy diet, alcohol consumption and inactive lifestyles (Cabinet Office, 2010: 6) and have therefore been subject to government policy aimed at improving decision making.

Perhaps less dramatically, there have also been attempts to influence individuals' behaviour in other areas. The most substantial recent reform drawing upon behavioural insights in the area of personal finance has been the introduction of the new workplace pension scheme in the UK starting in 2012. In the past, employees had to 'opt in' to pension schemes and many individuals did not do so - even though such schemes could be very advantageous. Under the new arrangements, employees are placed in a scheme and have to 'opt out' if they do not wish to be. This change of the default position is expected to make a substantial difference to the coverage of pension schemes in the UK. The importance of inertia in consumer behaviour is well known in the financial services sector, for example by the banks in attracting student customers knowing they will be probably be reluctant to move their accounts later.

It was this type of approach that led to the setting up of the Behavioural Insights Team (BIT) in July 2010. The aim of was to help the new UK Government develop and apply lessons from behavioural economics and behavioural science to public policy making. This was the result of the Conservative Party's increasing interest in the approach of behavioural factors and a preference in some contexts for the use of persuasion rather than regulation to influence behaviour. A direct link with the behavioural literature took place when the book Nudge by Thaler and Sunstein (2008) became 'required reading' on a 2008 summer reading list for Conservative Members of Parliament. Apparently this was because Thaler and Sunstein argue that sometimes people need a gentle push to do the right thing, a view seemingly consistent with the Conservative Party's tax and welfare policies. For this reason the Behavioural Insights Team is often known as the 'nudge unit'. It is charged with increasing understanding of behavioural approaches as well as developing specific policies. Its first projects have included reports on health, organ donation, charitable giving, consumer empowerment, energy use, fraud, error and debt.

This paper assesses the reports of the Behavioural Insights Team mentioned above in the light of the behavioural economics research literature. It begins in the following section by considering economic justifications for intervention in individual decision-making. Section 3 turns to the concept of 'nudging' and examines some limitations and arguments relating to the use of this approach. Section 4 gives a brief description of behavioural economics and some prominent behavioural issues and section 5 
examines the work of the Behavioural Insights Team. Section 6 draws some conclusions.

\section{AN ECONOMIC CASE FOR INFLUENCING CONSUMER DECISIONS}

Behavioural arguments have long been recognised as providing possible justification for influencing consumer decisions. For example, Pigou suggested that individuals may have a defective 'telescopic faculty' and that:

There is wide agreement that the State should protect the interests of the future in some degree against the effects of our irrational discounting and of our preference for ourselves over our descendants (Pigou, 1932, I, II, 7).

However, possibly the clearest economic justifications more generally for trying to influence consumer decisionmaking comes from Public Finance and the basic theory was clearly laid out in Richard Musgrave's (1959) classic text on the subject. Markets do not always perform efficiently and there are arguments for public intervention regarding public goods, external effects and 'merit wants'. Public goods that are 'non-excludable' in the sense that they can be consumed whether or not consumers pay for them are unlikely to be provided at the appropriate levels by commercial firms. Public goods may also have the characteristics of 'non-rivalness' in that everyone can consume the output collectively without depriving anyone else.
National defence is an example of a public good with both such characteristics. External effects are those associated with economic costs and benefits involving third parties not involved in the original economic decisions so there may again be a case for government intervention. An example here is pollution. These are straightforward cases where costs and benefits diverge and it is hard to see how nudging would provide an adequate solution.

However probably the issue with the most direct relevance to nudging concerns 'merit wants'. According to Musgrave, these are 'considered so meritorious that their satisfaction is provided for through the public budget over and above what is provided through the market and paid for by private buyers' Musgrave (1959: 13). Musgrave rules out the imposition by a ruling group of its own values on others as authoritarian and inconsistent with a model based on a democratic society. However, there remains scope for the public provision of merit wants in certain areas. He gives the examples of health and education where free public provision benefit the pupil or patient but, in addition to this, 'everyone stands to gain from living in a more educated or healthier community' (op. cit.). As this particular argument relating to merit goods relies on the collective benefits to others, public provision is clearly justified but nudging again does not seem to be directly relevant as the main policy instrument.

Nevertheless 'merit wants' may also describe direct benefits to individuals over and above the amount they may 
choose to consume if left entirely to themselves. Musgrave suggests, for instance, that the benefits of "education are more evident to the informed than the uninformed' and this may justify the public provision of education in the interests of children, "the freedom to belong may override the freedom to exclude, and so forth' Musgrave (1959: 14). As well as 'merit goods' of this sort, where consumer decision-making may be faulty, there may also be 'merit bads' when individuals consume more than is good for them. In such situations there may be a strong case for modifying the principle of consumer sovereignty. A further merit want argument advanced by Musgrave is that the "ideal of consumer sovereignty and the reality of consumer choice in high-pressure markets might be quite different things' (op. cit.). So there may be a case for counteracting distorted preference patterns and trying to influence individual decision-making.

\section{NUDGING}

In its widest sense nudging might be taken to mean any attempt short of statutory regulation to influence individuals' behaviour. It might be held therefore that the use of the tax system already supplies plenty of nudges with tax concessions for 'good' behaviour - such as savings in a pension scheme and additional tax for 'bad' behaviour - for example with alcohol, pollution and tobacco taxes. Individuals can continue to choose to avoid 'good' behaviour by not contributing to a pension to continue to or drink and smoke but there would be adverse monetary consequences. However, in the present context, such incentives are not counted as nudges but as a separate category of policy.

In their book Nudge, Thaler and Sunstein take a precise view of nudging:

A nudge... is any aspect of the choice architecture that alters people's behaviour in a predictable way without forbidding any options or significantly changing their economic incentives. To count as a nudge, the intervention must be easy and cheap to avoid...Putting the fruit at eye level counts as a nudge. Banning junk food does not. Thaler and Sunstein (2008: 6).

Following the approach of behavioural economics, Thaler and Sunstein go on to differentiate between homo economicus or 'Econs' from homo sapiens or 'Humans'. An Econ can 'think like Albert Einstein, store as much memory as IBM's Big Blue, and exercise the willpower of Mahatma Gandhi' (p. 6). A Human can't. 'Humans predictably err' (p. 7). A nudge is then 'any factor that significantly alters the behaviour of Humans, even though it would be ignored by Econs' (p. 8).

Econs respond primarily to incentives - such as a tax on tobacco - and humans respond to incentives as well. This approach makes clear that behavioural economics complements and extends mainstream economics rather than replaces it. This is illustrated by Econs. Thus: 
By properly deploying both incentives and nudges, we can improve our ability to improve people's lives, and help solve many of society's major problems. And we can do so while still insisting on everyone's freedom to choose (Thaler and Sunstein, p. 8).

The word 'nudge' is presented by Thaler and Sunstein as an acronym as six principles of good choice architecture as shown in Table 1.

This is not a new phenomenon. Using the Thaler and Sunstein definition, much commercial marketing falls in this category. Indeed marketing might in some ways be described as the art of nudging. It is reasonable to point out that marketing professionals were far ahead of the academics in understanding and then exploiting behavioural factors in influencing consumer choice. Furthermore, governments use nudging in the narrow sense extensively in publicity campaigns of one sort of another exhorting the public to do this or not do that. These include campaigns regarding giving up smoking ('Cancer cures smoking') avoiding harmful exposure to the sun in Australia ('Slip, Slap, Slop') and drink driving ('Stay Alive, don't drink and drive'). It is clear therefore that nudging is used extensively already. The contribution of Thaler and Sunstein is to link the concept to behavioural economics and the considerable amount of behavioural evidence now available.

There is a variety of nudging involving a 'required choice' or 'mandated choice' (Thaler and Sunstein, 2008: 6). This occurs when the choice architect forces individuals to make their own choice. An example relates to organ donation by deceased donors. There is an explicit choice 'opt-in' position where active consent is required to become an organ donor or there is the opposite position of 'presumed consent' where everyone is considered to be willing to donate organs in the event of their death unless they have specifically 'opted out'. Between these positions is mandated choice where, for example, individuals applying for a driving licence might be required to make such a choice.

\subsection{Is Nudging a Good Policy Instrument?}

Since nudging in the Thaler and Sunstein sense does not in its pure form inhibit freedom of choice and is designed only to

\section{Table 1. Nudge}

\begin{tabular}{|l|l|}
\hline iNcentives & Prices and markets \\
\hline Defaults & People tend to take the option that requires the least effort \\
\hline Give feedback & The best way to help Humans improve \\
\hline Expect error & System should be designed to expect mistakes \\
\hline Understanding mappings & Relationship between choice and outcomes \\
\hline Structure complex choices & To cope with numerous alternatives \\
\hline
\end{tabular}

Source: Thaler and Sunstein (2008) 
improve individuals' decisions, it seems to be a good choice of policy instrument. However, there has been debate ranging from criticism of Thaler and Sunstein's basic idea to more practical aspects.

A fundamental question is whether the government knows better than individuals what is in individuals' own best interests and furthers those interests and not some other agenda. For instance, regarding health, people do not behave as if their lives are of infinite value. Might it be legitimate to choose a life of indulgence rather than a possibly longer one of virtue?

This raises philosophical considerations regarding both liberty and paternalism. In Nudge, Thaler and Sunstein endorse the term 'libertarian paternalism'. They use 'libertarian' to modify the word 'paternalism' by meaning 'liberty preserving' and the paternalistic aspect is based on the claim that it is legitimate to influence individual's behaviour to make their lives 'longer, healthier and better' (p. 5). They then define libertarian paternalism 'to include actions, rules and other nudges that can be easily avoided by opting out' (p. 248) though concede they have no clear definition of 'easily avoided' and that individuals should be allowed to make their own choices at the lowest possible cost.

For some 'libertarian paternalism is an oxymoron'(Vallgårda, 2012: 200) -a view specifically addressed by Sunstein and Thaler (2003) who hold that it is possible to influence behaviour while respecting freedom of choice. Others such as Amir and Lobel (2008: 2098) have pointed out possible limitations in the concept such as its implementation entails costs, has effects on the distribution of income and are 'inevitably value driven'. Thaler and Sunstein (2008: 5) state their understanding of the word 'paternalistic' is that it applies to a policy that "tries to influence choices in a way that will make choosers better off, as judged by themselves' (emphasis in the original). Hausman and Welch (2010) argue that Thaler and Sunstein's meaning of paternalism is giving good advice and rational persuasion for the good of the individual while treating them as free individuals. This is not the traditional meaning attached to paternalism which refers to taking choices for individuals for their own good but not necessarily with their agreement, indeed it might include limiting individuals' freedom against their will. As Vallgårda (2012: 202) puts it, there are no objections to the paternalistic dimension but there could be several relating to the libertarian perspective.

However, there has also been significant criticism of particular aspects. In terms of fairness, Goodwin (2012: 89) has suggested that 'nudging is inherently unfair' as people end up with different outcomes. Another criticism is that nudging is manipulative. Government nudging may be offset by market nudging in the opposite direction. Furthermore, nudging may be unable to deliver the substantive changes required to deal with the major challenges facing society. There is some substance in each of these views depending on the issue involved and the context. 
A particular criticism has been raised with respect to mandated choice in the case of the supply of organs donated following death. The situation regarding Thaler and Sunstein's (2008: ch. 11) argument for requiring individuals applying for a driving licence to choose whether to donate their organs might be more complex than appears at first sight. Whyte et al. (2012:32) argue that the 'appropriateness of nudges depends both on understanding people's general cognitive biases and on accounting for the meaning they attribute to particular contexts' and show how the situation may be a complex one involving the family of the deceased. There is a general relevant point here and it matches the conclusion of Amir and Lobel (2008: 2137) that the prescriptive nature of nudge initiatives means they should be cautious and must be carefully designed to address each behavioural bias appropriately. Nudging is also not the only possible stategy of this sort that might be deployed by governments. John et al. (2009), examine nudging together with a second strategy for influencing civic behaviour which they call 'think'. More formally, they denote this strategy as 'deliberative democracy' since it describes a process by which citizens, through deliberation and dialogue, may make more informed and better choices regarding collective decisions. They suggest there are ways in which the two strategies of 'nudge' and 'think' may reinforce each other.

Finally nudging on its own may well be insufficient to achieve policy aims. In its report on behaviour change, The Science and Technology Select Commit- tee (2011) of the House of Lords in the UK quite reasonably came to a central conclusion that effective policies often employ a range of measures and nonregulatory actions, including 'nudges', are less likely to be effective. Nudges are clearly used where something short of formal regulation is deemed appropriate and, as the Select Committee (para. 8.1) also pointed out, government intervention to change individuals' behaviour will often be controversial.

\section{BEHAVIOURAL ECONOMICS AND BEHAVIOURAL ISSUES}

Behavioural economics has been described as increasing the "explanatory power of economics by providing it with more realistic psychological foundations' (Camerer and Loewenstein, 2004: 3) though it also draws on other disciplines. Its approach involves modifying 'the standard economic model to account for psychophysical properties of preference and judgement, which create limits on rational calculation, willpower and greed' (Camerer and Malmendier, 2007: 235).

Insights from behavioural economics have considerable potential to contribute further to the development of government policy and practice, for example in the important field of taxation (James, 2006, 2012 and 2014). In terms of specific issues, behavioural economics covers a wide range of topics related to decision-making. As the Cabinet Office and Institute for Government (2010:16) point out, one 'weakness of the literature 
around behavioural economics is there are now literally hundreds of different claimed effects and influences'. In order to gain an idea of the most important topics the present author surveyed the indexes of three standard behavioural economics texts, Camerer, Lowenstein and Rabin (2004) Schwartz (2008) and Wilkinson (2008) to add the number of pages referenced. Of course, this was not a precise exercise. Many of the concepts overlap - for example 'decision-making' with a variety of effects and there are considerable differences in the way different books are indexed. However, some concepts were referenced considerably more than others. All those referenced on more than 50 pages in the three books together are shown in Table 2. Three were referenced on more than 100 pages. The issue most referenced by far was fairness, and even more so if fairness is taken as including 'inequality aversion, followed by prospect theory and emotional factors. Other frequently referenced behavioural issues are shown in Table 3.

Some of these require a few words of explanation. Prospect theory ex- amines decision-making involving risk and probabilities and presents a considerable challenge to traditional utility theory. In particular it predicts that individuals will give less weight to uncertain outcomes than to certain ones. It was developed by Kahneman and Tversky (1979) and its impact is hard to underestimate - as of $30 \mathrm{Sep}$ tember 2014 google scholar indicated that paper had been cited 30,351 times. Framing refers to the possibility that an individual's choices may be influenced by how they are 'framed' (Kahneman and Tversky, 1981). As Kahneman (2011: 272) later described it: 'large changes of preferences... are sometimes caused by inconsequential variations in the wording of a choice problem'. Anchoring refers to a tendency for individuals to be over-influenced by the first information (the anchor) they have in making a particular decision. Subsequent pieces of information may then be judged in the light of their distance from the anchor.

Although the effects listed in Tables 3 and 4 by no means cover all the signifi-

\section{Table 2. Most referenced behavioural topics}

\begin{tabular}{|l|l|}
\hline Decision-making & Covers a variety of factors \\
\hline Emotional factors & Rather than carefully thought through factors \\
\hline Fairness & Views on the relative position of different individuals \\
\hline Framing & The way choices are presented to an individual \\
\hline Loss aversion & Losses cause more pain than equivalent gains cause pleasure \\
\hline Mental accounting & Individuals can have separate accounts mentally for psychologically separate outcomes \\
\hline Prospect theory & Examines decision-making involving risk and probabilities \\
\hline Reciprocity & Responses to the behaviour of others \\
\hline Time preference & Preference for utility to be received sooner rather than later \\
\hline
\end{tabular}

Note: complied by the author 
Table 3. Other prominent behavioural issues

\begin{tabular}{|l|l|}
\hline Altruism & Concern for the welfare of other people \\
\hline Anchoring & Over-reliance on the first piece of information received \\
\hline Bounded rationality & Rational decision-making may be limited by a range of factors \\
\hline Choice bracketing & Choices taking account of interdependencies among decisions \\
\hline Context effects & Ways in which preferences depend on other options available \\
\hline Endowment effects & The level of initial wealth may influence decisions \\
\hline Evolutionary considerations & Human behaviour as the outcome of evolution \\
\hline Learning effects & The effects of experience \\
\hline Money illusion & Decisions based on nominal rather than real values of money \\
\hline Self control & Ability to avoid temptation which carries long term disadvantage \\
\hline Status quo bias & An exaggerated preference for the status quo \\
\hline
\end{tabular}

Note: complied by the author

Table 4. MINDSPACE

\begin{tabular}{|l|l|}
\hline Messenger & Who delivers the message may be important \\
\hline Incentives & Affect behaviour in different ways \\
\hline Norms & Individuals try to conform to group norms \\
\hline Defaults & Inertia an important factor in behaviour \\
\hline Salience & The more specific and salient the more influence \\
\hline Priming & Previous awareness may increase acceptability \\
\hline Affect & The emotional dimension of a response \\
\hline Commitments & Trying to stick to promises and reciprocate \\
\hline Ego & Behaviour towards promoting image of self \\
\hline
\end{tabular}

Source: Cabinet Office and Institute for Government (2010)

cant effects, they present a clear indication of the sort of insights behavioural economics has to offer.

\section{BEHAVIOURAL INSIGHTS TEAM}

As already stated, the Behavioural Insights Team (BIT) was set up in 2010 to apply behavioural factors to the development of public policy. Its objective is to find 'intelligent ways to encourage, support and enable people to make better choices for themselves' (Cabinet Office, 2010). In terms of particular applications, the BIT has been very active across government activity and its website also includes seven significant published papers in specific areas (Behavioural Insights Team, 2014). One is concerned with methodology. Of the six others, two are concerned with health, broadly defined, one with charitable giving and the other three are associ- 
ated with consumer financial matters. The two applying to health are Applying Behavioural Insight to Health (Cabinet Office, 2010) and Applying Behavioural Insights to Organ Donation (Cabinet Office and Department of Health, 2013) and are well focused on behavioural factors as is the report on Applying Behavioural Insights to Charitable Giving (Cabinet Office, 2013). The three on consumer financial matters include behavioural insights but draw more heavily on traditional approaches. The first of these three reports is concerned with empowering consumers and is entitled Better Choices: Better Deals (Cabinet Office and Department for Business Innovation and Skills, 2011). A second document - Behaviour Change and Energy Use (Cabinet Office, 2011), sets out to examine how behavioural lessons can be used to help people to save energy and money. A third one Applying Behavioural Insights to Reduce Fraud, Error and Debt (Cabinet Office, 2012) explores ways by which public bodies might tackle these problems.

In addition to these specific reports, the Cabinet Office and Institute for Government (2010) publication applies behavioural approaches to policy in general terms. This report focuses on 'nine robust influences on human behaviour' which 'have been repeatedly found to have strong impacts on behaviour' Dolan et al. (2012). This was condensed into a manageable 'checklist' which took the form of the mnemonic MINDSPACE shown in Table 4 . The nine headings making up MINDSPACE incorporate many of the issues listed in Tables 2 and
3 , for example, 'incentives' in Table 4 incorporates prospect theory.

\subsection{Health}

Health is an area of tremendous potential for the application of behavioural insights. For example, the BIT health report cited above provides evidence that in the UK around two-thirds of smokers would like to give up the habit. There are also many more issues in health that offer scope for the application of behavioural insights. Indeed many of the problems are behavioural - as indicated at the beginning of the paper - behavioural and lifestyle factors contribute significantly to about half of all deaths in the UK.

The BIT behavioural health paper was therefore able to employ all of the nine influences identified in MINDSPACE, as shown in Table 5 and most of the issues identified as most frequently referenced in the analysis of behavioural texts in the previous section.

\subsection{Organ Donation}

The publication Applying Behavioural Insights to Organ Donation (Cabinet Office and Department of Health, 2013), presents one of the largest randomised controlled trials ever undertaken in the UK. It reports that around 90 per cent of people say they support organ donation but less than a third are registered. On average three people a day die in the UK because not enough organs are available for transplant.

The experiment tested the effect of different messages on a government website that encourages registration as 
Table 5. MINDSPACE and health

\begin{tabular}{|l|l|}
\hline Smoking & Ego, Incentives, Commitment and Salience \\
\hline Organ donation & Salience and Defaults \\
\hline Teenage Pregnancy & Norm, Messenger and Ego \\
\hline Alcohol & Norms and Salience \\
\hline Diet and Weight & Priming, Salience and Affect \\
\hline Diabetes & Incentives and Salience \\
\hline Food hygiene & Salience \\
\hline Physical activity & Norms, Affect and Salience \\
\hline Social Care & Commitment \\
\hline
\end{tabular}

Source: Cabinet Office (2010)

an organ donor. It ran for five weeks during which over a million people saw one of the eight messages being tested and each message was viewed by over 135,000 individuals. Variant 1 was the control page which simply asked 'Please join the NHS Organ Donor Register'. This request appeared in all the variants but in the first one it appeared without additional information and formed a benchmark against which all the other variants could be compared.

The second variant used the idea of presenting a social norm and added to the basic message 'every day thousands of people who see this page decide to register' (see Table 6). Variants 3 and 4 were also based on the idea of a social norm but included extra images to enhance the message. Variant 5 used the idea of a 'loss frame' - the idea that people are loss adverse and might consider a loss worse than an equivalent gain - and therefore contained the basic message together with 'Three people die every day because there are not enough organ donors'. Variant 6 used the concept of a 'gain frame' - that sometimes individuals prefer a positive message - so in this case the additional message was 'You could save or transform up to 9 lives as an organ donor'. Variant 7 was based on fairness and reciprocity and had the additional message 'If you need an organ transplant would you have one? If so please help others'. The final variant

Table 6. Additions to the basic message of 'please join the NHS organ donor register'

\begin{tabular}{|l|l|}
\hline \multicolumn{1}{|c|}{ Concept } & \multicolumn{1}{c|}{ Additional Message } \\
\hline Social norm & Every day thousands of people who see this page decide to register \\
\hline Loss frame & Three people die every day because there are not enough organ donors \\
\hline Gain frame & You could save or transform up to 9 lives as an organ donor' \\
\hline Fairness and reciprocity & If you need an organ transplant would you have one? If so please help others. \\
\hline Action & If you support organ donation please turn your support into action \\
\hline
\end{tabular}

Source: Cabinet Office and Department of Health, 2013 
tried to spur people into action with 'If you support organ donation please turn your support into action'.

Only one of the variants had a lower registration rate then the control variant which consisted of the basic message alone. This was variant 3 , one of three that included the message 'Every day thousands of people who see this page decide to register' but with a group photograph. Variants 2 and 4, which contained the same additional message but not the group photograph, as well as variants 5-8, significantly increased registration rates as compared to the control group. The one with the best registration rate was variant 7 based on fairness and reciprocity. It may be no coincidence that fairness was the behavioural issue most commonly indexed in the survey of behavioural books reported in section 4 above. It also drew on most of the other issues identified in that survey listed in Table 2 and almost all of the MINDSPACE factors shown in Table 4.

\subsection{Charitable Giving}

The paper on applying behavioural insights to charitable giving (Cabinet Office, 2013) reports the results of five trials set up to test the effectiveness of four behavioural insights. The first was to 'make it easy'. The second insight was to 'attract attention', for example by using personal messages and encouraging reciprocity with small gifts to potential donors. The third was to 'focus on the social' by trying to establish social and group norms. The fourth insight was 'timing matters' - for example appeals for donations might be more effective in December rather than January and people might be more prepared to agree to future (increases in) donations than equivalent amounts today. The five trials provided strong evidence of the effectiveness of using these behavioural insights to increase charitable giving. Like the project on organ donation, the charitable giving project drew on almost all of the MINDSPACE factors but fewer of the other behavioural issues identified in section 4 than the two papers considered above. This may be because of charitable giving is different from health issues and organ donation but there seems to be scope for further use of behavioural concepts in this area as well. However, none of the following three papers on financial decisions drew so heavily on behavioural concepts as did the three examined above.

\subsection{Consumer Empowerment}

The first of the papers with a financial dimension is Better Choices: Better Deals (Cabinet Office and Department for Business Innovation and Skills, 2011). This project reflected a 'consumer empowerment strategy' designed to put 'information and influence into the hands of consumers and [help] secure a significant power shift to citizens and communities in practical terms' (p. 4). The main areas are shown in Table 7.

Some of the suggestions therefore include annual credit card statements containing information about fees and how to switch provider. Another is working with energy suppliers to provide better information about tariffs. 
Table 7. Empowering consumers

\begin{tabular}{|l|}
\hline \multicolumn{1}{|c|}{ Aim to Enable Individuals to Make Better Choices and Obtain Better Deals By: } \\
\hline Encouraging businesses to provide more information \\
\hline Helping consumers to band together to get better deals \\
\hline Enabling better access to complaints and performance data \\
\hline Helping to empower the least powerful consumers \\
\hline
\end{tabular}

Source: Cabinet Office and Department for Business Innovation and Skills, 2011.

The paper, however, is much more in the tradition of mainstream rather than behavioural economics or behavioural finance in concentrating on improving the market in its role of allocating resources. The first main issue in the paper is improving the information provided by suppliers and others to make it easier for consumers to make informed decisions. A second, which the paper describes as 'the power of the crowd', is in fact a series of measures aimed at empowering consumers by encouraging them to work together. An initiative here is the development of collective purchasing deals. This fits neatly in mainstream economic analysis. A similar initiative is promoting the integrity of consumer feedback and price comparison sites. Another dimension is 'empowering the vulnerable' by providing them with additional support. Again this is a very worthy aim but not a reflection of developments in behavioural insights. Finally, there is a dimension related to a new role for government working in partnership with business. Once again, there may be strong arguments for this initiative but, as with the other dimensions, it is not a development particularly based on the contributions of behavioural economics and behavioural finance. Compared to the three papers examined above, this one drew on relatively few of the concepts contained in MINDSPACE or the other behavioural issues identified above.

\subsection{Energy Use}

A second document on financial issues - Behaviour Change and Energy Use (Cabinet Office, 2011) also followed the traditional economic approach to some extent - for example in attempts to improve the information available to consumers. However, this report makes much better use of behavioural insights particularly those listed in MINDSPACE. Table 8 summarises the main use of such behavioural contributions.

Time preference is one of the issues given considerable attention in the behavioural texts analysed in section 4 and acknowledges that individuals might put a higher valuation on present rather than future costs and benefits. In the context of energy use, the report pointed out that measures to improve energy efficiency usually involve an immediate and often large cost but the benefits may be spread over a very long period of time. The report therefore explores the possibilities of rewarding consumers to improve energy efficiency by the use 
Table 8. Energy use

Discounting the future: People discount the long term benefits of improvements in energy efficiency so moves to design immediate rather than long-term rewards.

Social norms: Approaches involving improving comparative energy consumption information and also whether it is possible to encourage the diffusion of norms through existing social networks.

Defaults: Successful interventions have involved changing defaults such as the timing of heating systems turning on and off.

Mental accounting and winter fuel payments.

Source: Cabinet Office, 2011.

of immediate rewards rather than small benefits over many years. A similar approach involves attempts to establish social norms favourable to the efficient use of energy and default positions regarding the timing of heating systems. Mental accounting describes a tendency for individuals to keep different sorts of spending in separate 'mental accounts'. The report cited evidence that households receiving the government 'Winter Fuel Allowance' are around 14 times more likely to use the money on fuel than if they had been given the money in other ways. This report also drew on other concepts from MINDSPACE - for example 'getting the messenger right at the salient moments'. For instance, at the point of moving house, people may be more amenable to fitting energy efficient products.

\subsection{Fraud, Error, and Debt}

The third BIT paper relating to financial issues was concerned with fraud (Cabinet Office, 2012). This report also makes use of behavioural insights - and offers a specific list of lessons which are shown in Table 9.

Some of the report is concerned with the usual incentives and improvement in information but there is more reliance on the contribution of behavioural factors than appeared in the paper on consumer empowerment.

The work of the BIT examined here varies considerably in its use of behav-

Table 9. 'Lessons from behavioural science'for reducing fraud, error and debt

\begin{tabular}{|l|l|}
\hline Insight 1 & Make it easy \\
\hline Insight 2 & Highlight key messages \\
\hline Insight 3 & Use personal language \\
\hline Insight 4 & Prompt honesty at key moments \\
\hline Insight 5 & Tell people what others are doing \\
\hline Insight 6 & Reward desired behaviour \\
\hline Insight 7 & Highlight the risk and impact of dishonesty \\
\hline
\end{tabular}

Source: Cabinet Office, 2012. 
ioural insights. The report on health makes great use of such insights in a wide range of contexts as do the reports on organ donation and charitable giving. At the other extreme, the report on consumer empowerment draws little on such contributions but is based on more mainstream economic analysis. The other two reports on financial issues are between these two situations, making some use of behavioural evidence but nowhere near as much as the health, organ donation and charitable giving reports. There seems to be a great deal of scope for more use of behavioural insights in financial matters as well as other areas of individual behaviour.

\section{CONCLUSION}

There are economic arguments for influencing individuals' behaviour, including 'merit wants' as outlined by Musgrave (1959). The idea of 'nudging' individuals in their decision-making has some advantages over more rigid controls, not least in that it preserves consumer sovereignty in the sense that the final decisions are, in principle, still made by consumers. Nevertheless the complexities involving different behavioural factors and particular contexts indicate that nudge initiatives should be developed carefully in each case.

The work of the UK Behavioural Insights Team has applied a range of insights from the behavioural economics literature. Drawing on the results of the survey reported in section 4 , it is shown that reports of the BIT analysed in this paper drew directly on all of the
9 most referenced behavioural topics. The reports also used most of the group of 11 insights which were the next most frequently cited in the literature. It is interesting to consider why the work on health policy, organ donation and charitable giving applied behavioural insights to a considerable extent while two of the reports on financial aspects did so to a lesser extent and one of the reports hardly at all. It seems likely that the former group of topics have more potential for the application of behavioural insights but, as the literature on behavioural finance demonstrates, considerable potential exists in this area as well. It is clear from the work of the Team that applying behavioural insights can lead to better decisions for many people and there is enormous scope for further applications.

The implications of the work of the BIT for the theory and practice of nudging is that it does indeed have advantages over regulation in terms of preserving consumer choice and also that following a policy of nudging can establish better ways to contribute to desired outcomes. However, in practice, nudging may sometimes be a more complex policy instrument than is sometimes appreciated.

\section{ACKNOWLEDGMENT}

The author is grateful for the helpful comments of two referees and also the contributions from those attending the presentation of earlier versions of this paper at the Conference for the Advancement of Behavioural Econom- 
ics, University of Granada, Spain, July 12-15, 2012 and the ICEA - FAA Conference, University of Bucharest, June 20-21, 2014.

\section{REFERENCES}

Amir, O., \& Lobel, O. (2008). Stumble, predict, nudge: How behavioral economics informs law and policy. Columbia Law Review, 108, 2098-2137.

Behavioural Insights Unit. (2014). Publications. https://www.gov.uk/government/publications?departments[] $=\mathrm{b}$ ehavioural-insights-team accessed 14 June 2014.

Cabinet Office. (2010). Applying Behavioural Insight to Health. London: Cabinet Office. Behavioural Insights Team.

Cabinet Office. (2011). Behaviour Change and Energy Use. London: Cabinet Office Behavioural Insights Team.

Cabinet Office. (2012). Applying Behavioural Insights to Reduce Fraud, Error and Debt. London: Cabinet Office Behavioural Insights Team.

Cabinet Office. (2013). Applying Behavioural Insights to Charitable Giving. London: Cabinet Office Behavioural Insights Team.

Cabinet Office \& Department for Business Innovation and Skills. (2011). Better Choices: Better Deals. London: Cabinet Office Behavioural Insights Team.
Cabinet Office \& Department of Health. (2013). Applying Behavioural Insights to Organ Donation. London: Cabinet Office Behavioural Insights Team.

Cabinet Office \& Institute for Government. (2010). MINDSPACE, Influencing Behaviour through Public Policy. London: Cabinet Office.

Camerer, C. F., \& Lowenstein, G. (2004). Behavioral economics: past, present, future. In C. F. Camerer, G. Lowenstein, \& M. Rabin (Eds.), Advances in Behavioral Economics (pp. 3-51). Princeton, NJ: Princeton University Press.

Camerer, C. F., Lowenstein, G., \& Rabin, M. (Eds.), Advances in Behavioral Economics. Princeton, NJ: Princeton University Press.

Camerer, C.F., \& Malmendier, U. (2007). Behavioral economics of organizations. In P. Diamond \& H. Vartiainen (Eds.), Behavioral Economics and Its Applications (pp. 235-290). Princeton, NJ: Princeton University Press.

Dolan, P., Hallsworth, M., Halpern, D., King, D., Metcalfe, R., \& Vlaev, I. (2012). Influencing behaviour: The mindspace way. Journal of Economic Psychology, 33(1), 264-277. doi:10.1016/j.joep.2011.10.009

Goodwin, T. (2012). Why we should reject 'nudge'. Politics, 32(2), 85-92. doi:10.1111/j.1467-9256.2012.01430.x 
Hausman, D. M., \& Welch, B. (2010). Debate: To nudge or not to nudge. Journal of Political Philosophy, 18(1), 123-136. doi:10.1111/j.1467-9760.2009.00351.x

James, S. (2006). Taxation and the contribution of behavioral economics. In M. Altman (Ed.), Foundations and extensions of behavioral economics: A handbook (pp. 589-601). New York, NY: M.E. Sharpe.

James, S. (2012). Behavioral economics and the risks of tax administration. eJournal of Tax Research, 10(2), 345 $-363$.

James, S. (2014). The importance of fairness in tax policy: Behavioral economics and the UK experience. International Journal of Applied Behavioral Economics, 3(1), 1-12. doi:10.4018/ ijabe.2014010101

John, P., Smith, G., \& Stoker, G. (2009). Nudge nudge, think think: Two strategies for changing civic behaviour. The Political Quarterly, 80(3), 361-370. doi:10.1111/j.1467-923X.2009.02001.x Kahneman, D. (2011). Thinking, Fast and Slow. London: Penguin.

Kahneman, D., \& Tversky, A. (1979). Prospect theory: An analysis of decision under risk. Econometrica, 47(2), 263-292. doi:10.2307/1914185

Kahneman, D., \& Tversky, A. (1981). The framing of decisions and the psychology of choice. Science, 211(4481), 453-458. doi:10.1126/science.7455683 PMID:7455683
Musgrave, R. A. (1959). The Theory of Public Finance: A Study in Political Economy. New York: McGraw-Hill.

Pigou, A. C. (1932). The Economics of Welfare (4th ed.). London: Macmillan.

Schwartz, H. (2008). A Guide to Behavioral Economics, Higher Education Publications, Virginia: Falls Church.

Science and Technology Select Committee, House of Lords. (2011), Behaviour Change, 2nd Report of Session 2010-12, HL Paper 179, London: The Stationery Office.

Sunstein, C. R., \& Thaler, R. H. (2003). Libertarian paternalism is not an oxymoron. The University of Chicago Law Review. University of Chicago. Law School, 70(4), 1159-1202. doi:10.2307/1600573

Thaler, R. H., \& Sunstein, C. R. (2008). Nudge. New Haven: Yale University Press.

Vallgårda, S. (2012). Nudge - a new and better way to improve health? Health Policy (Amsterdam), 104(2), 200-203. doi:10.1016/j.healthpol.2011.10.013 PMID:22113151

Whyte, K. P., Selinger, E., Caplan, A. L., $\&$ Sadowski, J. (2012). Nudge, nudge or shove, shove-the right way for nudges to increase the supply of donated cadaver organs. The American Journal of Bioethics, 12(2), 32-39. doi:10.1080/1526516 1.2011.634484 PMID:22304518

Wilkinson, N. (2008). An Introduction to Behavioral Economics. Basingstoke: Palgrave Macmillan. 
Simon James is an Associate Professor in Economics in the Department of Organisation Studies at the University of Exeter Business School, an Honorable Member of the Society for the Advancement of Behavioral Economics, a Fellow of the Higher Education Academy and a Fellow of the College of Teachers. He has also held visiting positions at six universities overseas including the Australian National University and the most recent was a Visiting Erskine Fellowship at the University of Canterbury, New Zealand in 2013. He holds an MBA as well as Masters degrees in Economics, Law, Education and Educational Management, and the subject of his PhD was 'Taxation and Economic Decisions'. He has published over 60 research papers and 15 books. 


\title{
CALL FOR ARTICLES
}

\section{International Journal of Applied Behavioral Economics}

\author{
An official publication of the Information Resources Management Association
}

\begin{abstract}
MISSION:
The mission of the International Journal of Applied Behavioral Economics is to examine the main applications of Behavioral Economics in business and organizations, both in classical terms as well as influenced by digitalization and new technologies. Behavioral Economics arises from research that shows human boundary rationality and failures in acting in "self"-interest, loss aversion, among others - influence the making of economic choices and decisions. Despite the importance of an interdisciplinary perspective, the practical applications of this research are not well represented. The journal promotes papers that show a direct link between Behavioral Economics and concrete, practical applications at a business and organizational level, with a special focus on the effects of technology implementation and usage on economic agents' perception, behavior, and decision-making processes. For this purpose, the journal serves as a distribution channel for research that contributes to theory and practice development in this knowledge domain.
\end{abstract}

\section{COVERAGE/MAJOR TOPICS:}

- Applications of behavioral economics findings in public policies

- Applied evolutionary economics and psychology

- Behavioral factors influencing supply and demand of health and health services

- Boundary rationality and impact on making decisions in business and organizations

- $\quad$ Branding/advertising issues and organization behavior

- Changes in economic behavior meaning in the globalization age

- Consequences of decisions, judgment and choices with respect to producers' results

- Consumer behavior, marketing and digital marketing in the globalization age

- Cross-cultural behavioral variation with impact on business and organizations

- Differences between market behavior and individual behavior and their implications in business

- Economic and social costs of addictive behaviors

- Economic and socio-psychological determinants of eorganizations' behavior

- $\quad$ Factors influencing preferences,judgment, choices, decisions and the way they impact consumer behavior

- Impact of new technologies on supply and demand of health and health services

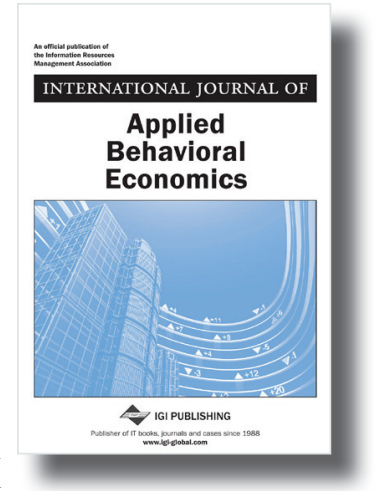

rationality in decision making process

- Impact of technology diffusion on wealth, consumption and happiness

ISSN 2160-9802 eISSN2160-9810 Published quarterly

- Impact of technology implementation in "procedural rationality" risk reduction

- Individual and organizational decision making: consumption and non-consumption related factors

- Inter-temporal choices with impact on savings and investments

- Loss aversion and risk evaluation at business and organizational level

- Methodological aspects in experimental economics with applications in business

- New technologies related to consumption and environment

- Rational behavior under imperfect competition with implications at business level

- Social and psychological impact of macroeconomic policies on business and organizational behavior

- The overconsumption society: determinants and effects in the globalization age

Ideas for Special Theme Issues may be submitted to the Editor-in-Chief.

$$
\begin{gathered}
\text { Please recommend this publication to your librarian. For a convenient easy- } \\
\text { to-use library recommendation form, please visit: } \\
\text { http://www.igi-global.com/IJABE }
\end{gathered}
$$

